\title{
Arthroscopy in the Elderly
}

\author{
Sqn Ldr J E Hambidge \\ FRCS (Ed), FRCS Orth, RAF \\ *Senior Registrar in Orthopaedic Surgery \\ Wg Cdr C Handley \\ MA, FRCS, RAF \\ Consultant Orthopaedic Surgeon
}

Princess Mary's Royal Air Force Hospital, Halton, Aylesbury, Bucks

SUMMARY: Arthroscopy of the knee is an accepted and widely practised diagnostic and therapeutic procedure. The role of arthroscopy in the elderly is examined in this study. The benefit of debridement in the control of symptoms in the degenerative knee even in this elderly population is demonstrated. Arthroscopy produced an improvement in $62.3 \%$ of patients and in those whose knees were being assessed for osteotomy or arthroplasty $55 \%$ have avoided further surgery.

\section{Introduction}

Arthroscopy is a commonly performed procedure, mainly in the young used in the management of suspected internal derangements. Previous studies have investigated the role of arthroscopy in the middle aged $(1,2)$ or those with degenerative disease $(3,4)$. Dandy $(5)$ in a recent editorial in the Journal of Bone and Joint Surgery reviewed the place of arthroscopic debridement of the osteoarthritic knee. He concluded that many questions remain unanswered about the indications and exact extent of arthroscopic surgery in the arthritic knee.

Richards and Longeran (6) reported that patients who were elderly and those with extensive disease did less well with arthroscopic surgery. Livesley and coworkers (7) have shown simple arthroscopic lavage to be of benefit.

The present study investigates the role of arthroscopy when used in the management of the elderly knee. The results of different arthroscopic procedures in those aged over sixty, often with extensive degenerative disease, is assessed.

\section{Patients and Method}

Between 12 July 1985 and 28 November 1989 sixty-six patients aged sixty and over underwent arthroscopy at Princess Mary's Royal Air Force Hospital, Halton. Fifty six complete case notes and follow up were available for study relating to sixty-nine arthroscopies performed during sixty-one admissions. The average age at arthroscopy was 69.0 years (range 60 years 4 months to 82 years). Thirty one of the patients were male, there were 36 left knees and eight cases were performed bilaterally.

Four cases were performed under local anaesthetic and a further ten without tourniquet. Nine knees had undergone previous surgery, seven previous arthroscopies, one open menisectomy and one patellectomy.
The indications for arthroscopy were considered to be:

Group (i) Assessment of the joint surface prior to proposed osteotomy or arthrop1asty. Forty patients $(58 \%)$.

Group (ii) Suspected internal derangement where further surgery was not being considered. Ten patients (14.5\%).

Group (iii) Those with known degenerative disease where further surgery was precluded by ill health. Sixteen patients $(23.2 \%)$.

Group (iv) Significant knee symptoms in patients being considered for hip arthroplasty. Three patients $(4.3 \%)$.

The average inpatient stay was 4.7 days, 1.6 days spent pre-operatively (1-6 days) and 3.1 days spent postoperatively (1-17 days).

Five patients had surgery deferred at pre-operative assessment due to pre-existing medical conditions - 2 with hypertension, 2 with renal impairment and one with diabetes.

There were two peroperative complications - minor acid reflux and transient hypotension.

There were eight postoperative effusions with prolonged inpatient stay.

Review was at the most recent clinic, at the time of discharge from follow up or when further surgery was performed. Mean follow up was 18.4 months (12-44 months). Results were assessed at the time of the most recent review. The patient being questioned directly about the overall result of surgery and their satisfaction with surgery.

\section{Results}

Twenty-eight patients were found to have meniscal damage felt by the operator to represent significant degenerative cleavage tears in an otherwise normal meniscus in 
an osteoarthritic joint compartment . These were managed by saucerization or subtotal menisectomy. In twenty-four knees degenerative meniscal damage was more widespread. Debridement with removal of meniscal fibrillation and chondral flaps with subsequent washout of the knee with at least one litre of saline was performed. In seventeen knees other pathologies were found such as loose bodies or enlarged fat pads.

The majority of knees had evidence of degenerative disease $(92.8 \%)$ and the distribution is displayed in Table 1. In males medial compartment osteoarthrosis in isolation was most frequently encountered $(50 \%)$ whereas in females bicompartmental osteoarthrosis was commonest (48.3\%). Overall the medial compartment was most frequently involved $-87.5 \%$ of males, $90 \%$ of females the lateral being involved in $40 \%$ of men and $72.4 \%$ of women.

Table 1.

Distribution of Osteoarthritis

\begin{tabular}{|c|c|c|c|c|c|c|c|c|c|}
\hline & \multicolumn{2}{|c|}{ Latr'l } & Medial & \multicolumn{2}{|c|}{ Bilat } & \multicolumn{4}{|c|}{ Tricomp Nil } \\
\hline & $\mathbf{N}$ & $\%$ & N $\%$ & $\mathbf{N}$ & $\%$ & $\mathbf{N}$ & $\%$ & $\mathbf{N}$ & $\%$ \\
\hline Male & 1 & 2.5 & 2050.0 & 10 & 25.0 & 5 & 7.2 & & 10.0 \\
\hline Female 29 & 2 & 6.9 & 724.1 & 14 & 48.3 & 5 & 17.2 & 1 & 3.4 \\
\hline Total 69 & 3 & 4.3 & 2739.1 & 24 & 34.8 & 10 & 14.5 & 5 & 7.2 \\
\hline
\end{tabular}

The patients subjective response to surgery is summarized in Table 2 and the patients final outcome in Table 3. Of the 24 patients who subsequently underwent further surgery 10 have had total knee replacement, 5 tibial osteotomy, 4 repeat arthroscopy, 3 total hip replacement and 2 knee fusion.

Table 2.

Patients Subjective Response

\begin{tabular}{|c|c|c|c|c|c|c|c|c|c|c|c|}
\hline \multirow{2}{*}{\multicolumn{2}{|c|}{ By Operation }} & \multicolumn{2}{|c|}{$\begin{array}{l}\text { Asympto- } \\
\text { matic }\end{array}$} & \multicolumn{2}{|c|}{ Improved } & \multicolumn{2}{|c|}{$\begin{array}{l}\text { Temp } \\
\text { Improve }\end{array}$} & \multicolumn{2}{|c|}{$\begin{array}{l}\text { No } \\
\text { Change }\end{array}$} & \multicolumn{2}{|c|}{$\begin{array}{l}\text { Not } \\
\text { Known }\end{array}$} \\
\hline & & $\mathbf{N}$ & $\%$ & $\mathbf{N}$ & $\%$ & $\mathbf{N}$ & $\%$ & $\mathbf{N}$ & $\%$ & $\mathbf{N}$ & $\%$ \\
\hline \multicolumn{2}{|c|}{ Menisectomy } & 6 & 21.4 & 9 & 32.1 & 3 & 10.7 & 9 & 32.1 & 1 & 3.6 \\
\hline \multicolumn{2}{|c|}{ Debridement } & 7 & 29.2 & 9 & 37.5 & 4 & 16.7 & 3 & 12.5 & 1 & 4.2 \\
\hline \multicolumn{2}{|l|}{$\begin{array}{l}\text { Other } \\
\text { by } \mathrm{OA} \text { :- }\end{array}$} & 5 & 29.4 & 7 & 41.2 & 2 & 11.8 & 3 & 17.6 & & \\
\hline Nil & 5 & 4 & 80.0 & & & & & & 20.0 & & \\
\hline Lateral & 3 & & & 3 & 100 & & & & & & \\
\hline Medial & 28 & 9 & 32.1 & 11 & 39.3 & 2 & 7.1 & 5 & 17.9 & 1 & 3.6 \\
\hline Bilateral & 23 & 3 & 13.0 & 8 & 34.8 & 6 & 26.1 & & 26.1 & & \\
\hline Tricomp & 10 & 2 & 20.0 & 3 & 30.0 & 1 & 10.0 & 3 & 30.0 & 1 & 10.0 \\
\hline \multicolumn{12}{|c|}{ By indication } \\
\hline Group (i) & 40 & 5 & 12.5 & 14 & 35.0 & 5 & 22.5 & 10 & 25.0 & 2 & 5.0 \\
\hline Group (ii) & 10 & 6 & 60.0 & 2 & 20.0 & & & & 20.0 & & \\
\hline Group (iii) & 10 & 7 & 43.7 & 8 & 50.0 & & & & 6.3 & & \\
\hline Group (iv) & 3 & & & 1 & 33.3 & & & & 66.6 & & \\
\hline Total & 69 & 18 & 26.1 & 25 & 36.2 & 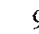 & 13.0 & 15 & 21.7 & 2 & 2.9 \\
\hline
\end{tabular}

Table 3.

Patient Outcome

\begin{tabular}{|c|c|c|c|c|c|c|}
\hline \multirow[b]{2}{*}{ By operation } & \multicolumn{2}{|c|}{ Discharge } & \multicolumn{2}{|c|}{$\begin{array}{l}\text { Further } \\
\text { Surgery }\end{array}$} & $\begin{array}{c}\text { Follow } \\
\text { Up }\end{array}$ & \multirow{2}{*}{$\begin{array}{l}\text { Lost } \\
\text { Follow: Up } \\
\text { N }\end{array}$} \\
\hline & $\mathbf{N}$ & $\%$ & $\mathbf{N}$ & $\%$ & N $\%$ & \\
\hline Menisectomy & 7 & 25.0 & 13 & 46.4 & 725.0 & 1 \\
\hline Debridement & 8 & 33.3 & 6 & 25.0 & 520.8 & \\
\hline Other & 5 & 29.4 & 5 & 29.4 & 423.5 & \\
\hline By indication & & & & & & \\
\hline Group (i) & 9 & 22.5 & 18 & 45.0 & 717.5 & \\
\hline Group (ii) & 5 & 50.0 & 2 & 20.0 & 110.0 & \\
\hline Group (iii) & 6 & 37.5 & 1 & 6.3 & 850.0 & 1 \\
\hline Group (iv) & & & 3 & 100.0 & & \\
\hline Total & 20 & 290 & 24 & 347 & 6232 & 9 \\
\hline
\end{tabular}

\section{Discussion}

After arthroscopy $62.3 \%$ of patients were improve $\vec{b}$ or asymptomatic. The best results were obtained in tholse patients with definitive pathologies other than meniseal, such as loose bodies, which were corrected at arthrome $\overrightarrow{0}$ y - $70.6 \%$ of patients having a good result. Partial medisisectomy in degenerative cleavage tears produced the pforest symptomatic improvement, $46.8 \%$ receiving no benes

As expected those without arthritis or with uniconartmental disease did better than those with more extgngive changes. Seventy five percent of those with no or u u partmental osteoarthrosis being improved whereas ofly $48.5 \%$ of those with more extensive disease hatis a good result.

Only $47.5 \%$ of those for whom arthroscopy was \%erformed as an assessment prior to further surgery were improved but in this group to date $55 \%$ have avoided arthroplasty or osteotomy due to symptomatic control $30 \mathrm{Of}$ those who underwent arthroscopy for symptomatic centrol as further surgery was not being considered 93 \% \% had a good result and the only patient undergoing furtiter surgery elected to have a repeat arthroscopy. There we poor results obtained when arthroscopy was performedfor those with hip disease and all of this group went on to fip arthroplasty. This study suggests that arthroscopy i@of benefit in the elderly. Better results are achieved in compartment osteoarthrosis and with minimal surgers to the meniscus. This form of surgery can be performe the unfit where arthroscopy can be undertaken withofut tourniqet in vascular disease or under local anaesthefic. The length the symptomatic improvement has not been demonstrated by this study but many patients requst repeat arthroscopy rather than arthroplasty.

\section{REFERENCES}

กิ

1. JACKSON R W, ROUSE D W. The results of paniual arthroscopic menisectomy in patients over 40 yegars of age. J Bone Joint Surg (Br) 1982; 64B: 481-485. 
2. McBride G G, Constine R M, Hoffman A A, CarSON R W. Arthroscopic partial medial menisectomy in the older patient. J Bone Joint Surg (Am) 1984; 66A: 547 - 551.

3. RAND J A. Arthroscopic management of degenerative meniscus tears in patients with degenerative arthritis. Arthroscopy 1985; 1: 253-258.

4. Sprauge N F. Arthroscopic debridement for degenerative knee joint disease. Clin Orthop 1981; 160: 118123.
5. DANDY D J. Arthroscopic debridement of the knee for osteoarthritis. J Bone Joint Surg (Br) 1991; 73B: 877 市 -878 .

6. Richards R H JR, Lonergan R P. Arthroscopic surgery for relief of pain in the osteoarthritic knee. ? Orthopaedics 1984; 7: 1705-1707.

7. Livesley P J, Doherty M, Needhoff M, Moulton A. Arthroscopic lavage of oestoarthritic knees. $J$ Bone Joint Surg (Br) 1991: 73B: 922-926. 